\title{
A RETROSPECTIVE ANALYSIS OF CLINICAL DIAGNOSIS, PREDICTABILITY AND FETO MATERNAL OUTCOME IN A CRITICAL PATIENTS ADMITTED IN OBSTETRIC INTENSIVE CARE UNIT IN A TERTIARY CARE CENTRE
}

\author{
M. Vijayasree ${ }^{1}$, K. Madhuri², N.C.H. Venugopal ${ }^{3}$, T. Narasinga Reddy ${ }^{4}$, Dilip Rampure ${ }^{5}$
}

\section{HOW TO CITE THIS ARTICLE:}

M. Vijayasree, K. Madhuri, N.C.H. Venugopal, T. Narasinga Reddy, Dilip Rampure. "A Retrospective Analysis of Clinical Diagnosis, Predictability and Feto Maternal Outcome in a Critical Patient admitted in Obstetric Intensive Care Unit in a Tertiary Care Centre". Journal of Evolution of Medical and Dental Sciences 2014; Vol. 3, Issue 03, January 20; Page: 601-607, DOI: 10.14260/jemds/2014/1872

ABSTRACT: INTRODUCTION: Care of the critically ill parturient is a unique challenge in obstetrics particularly because of its unpredictability. Hemorrhage, toxemia, anemia and septicemia are common causes of mortality and morbidity in these patients. Obstetric critical care in developing countries continues to be radically different from developed countries. AIMS AND OBJECTIVES: To analyze all cases of critically ill obstetric patients admitted to an obstetric intensive care unit in relation to causes for admissions, interventions required, course during their ICU stay and fetal maternal outcome. MATERIALS AND METHODS: A one year retrospective analysis of all obstetric admissions to the ICU at our referral hospital was conducted, observations made and results were analyzed. RESULTS AND ANALYSIS: There were 24 ICU admissions with mean age of 25.21 \pm 4.075 years and mean gestational age of $36.04 \pm 3.862$ weeks. Postpartum admissions were significantly higher $(83.33 \%, \mathrm{n}=20, \mathrm{P}<0.05)$ with more patients presenting with obstetric complications $(91.66 \%$, $\mathrm{n}=22, \mathrm{P}<0.01)$ as compared to medical complications $(8.32 \%, \mathrm{n}=2)$. Obstetric hemorrhage $(\mathrm{n}=15$, $62.5 \%)$ and hemodynamic instability $(\mathrm{n}=20,83.33 \%)$ were considered to be significant risk factors for ICU admission $(\mathrm{P}=0.000)$. Inotropic support was required in 22 patients $(91.66 \%)$ while 17 patients $(70.83 \%)$ required ventilatory support. The mean duration of ventilation $(30.17 \pm 21.65 \mathrm{~h})$ and ICU stay $(39.42 \pm 33.70 \mathrm{~h})$ were of significantly longer duration in survivors $(\mathrm{P}=0.01, \mathrm{P}=0.00$ respectively) versus non-survivors. The observed mortality $n=10,41.67 \%$ was significantly higher since ours is a referral tertiary center and delay in reaching the tertiary center from the place of occurrence of the mishap is a usual occurrence. CONCLUSION: Obstetric hemorrhage leading to hemodynamic instability remains the leading cause of ICU admissions and maternal mortality.

KEY WORDS: Critical care, Obstetric ICU, Prediction of maternal mortality.

INTRODUCTION: Care of the critically ill parturient is a unique challenge in obstetrics particularly because of its unpredictability. Hemorrhage, toxemia, anemia and septicemia are common causes of mortality and morbidity in these patients ${ }^{1}$. Obstetric critical care in developing countries, however, continues to be in the beginning stages ${ }^{2}$. An efficient scoring system for assessment of the severity and outcome in the critically ill obstetric patients would not only contribute to the assessment of the quality of patient care but would also enhance the risk stratification of pregnant patients in the evaluation of new therapies ${ }^{3}$. Various scoring systems like simplified acute physiology score (SAPS), acute physiology and chronic health evaluation (APACHE), and mortality probability models (MPM) have been used to predict the outcome of obstetric patients in the developed world ${ }^{4}$ but a dedicated ICU for obstetric patients is not yet widely available in developing countries 5,6 . With this background 
a one year retrospective analysis of all critically ill obstetric patients admitted to a dedicated obstetric ICU was done to characterize the causes, clinical course, treatment, and fetal maternal outcome.

MATERIALS AND METHODS: A one year retrospective analysis of all admissions to the obstetric ICU at Mamata General Hospital which is a referral center was conducted from July 2012 to June 2013. Patients included were critically ill women admitted during pregnancy as well as in the peurperium. The critical care team included Medical and surgical consultants, resident doctors from anesthesiology and obstetrics department and nurses posted in the ICU round the clock. Admission criteria were critically ill obstetric patients requiring ventilatory support or major organ supportive therapy. Facilities: Major equipments include multiparameter monitors like electro cardio gram (ECG), noninvasive blood pressure (NIBP)/ invasive blood pressure (IBP), heart rate (HR), oxygen saturation $\left(\mathrm{SpO}_{2}\right)$, respiratory rate and temperature monitors and microprocessor controlled ventilator with weaning modes for each bed, crash cart, defibrillator, suction machine and electrocardiographic machine are available in the ICU.

Data collection: An extensive proforma was developed to record the various data of patients admitted to obstetric ICU. The data noted included basic demographic data, obstetric and medical history, status before hospital admission, hospital and ICU course, treatment taken and the specific interventions done. Data of total obstetric mortalities were also noted from the hospital records. Basic demographic data included literacy levels and antenatal care provided. The distance travelled was also noted and the poor transport system in our area resulted in nearly two hours of travel to cover a distance of around fifty kilometers.

Scoring tool: In all ICU-admitted obstetric patients, MPM II score at the time of admission was calculated to assess the ICU outcome in terms of predicted death rate ${ }^{4}$. Data collected was analyzed using the appropriate Statistical method. A 'P value' of less than 0.05 was considered significant.

RESULTS: In the one year period from July 2012 to June 2013, the total admissions in the obstetric ICU were 24 women (ICU utilization rate was 0.14 per 100 deliveries) with 14 (58.33\%) survivors and $10(41.67 \%)$ non-survivors. The mean age of the patients was $25.21 \pm 4.075$ years and the mean gestational age was $36.04 \pm 3.862$ weeks. Demographic details of 24 patients according to maternal outcome are shown in TABLE - 1. No demographic data were found as a risk factor for maternal mortality $(\mathrm{P}>0.05)$. Postpartum admissions $(n=20,83.33 \%)$ were significantly more as compared to ante partum admissions $(n=4,16.66 \%, P<0.05)$. Obstetric complications $(n=22,91.66 \%)$ were a significant cause of severe morbidity as compared to non-obstetric (medical) complications ( $\mathrm{n}=2$, 8.34\% $\mathrm{P}<0.01)$ of which obstetric hemorrhage $(\mathrm{n}=15,62.5 \%)$ was found to be a significant risk factor for ICU admission, $(\mathrm{P}=0.000)$.TABLE - 2. Some of the associated medical conditions included nutritional anemia $(n=8,33.33 \%, P=0.010)$, jaundice $(n=2,8.33 \%)$, mitral valve disease $(n=1,4.16 \%)$ and upper respiratory tract infection (URTI) $(n=1,4.16 \%)$. This patient of URTI was already septicemia with hemodynamic instability, who underwent emergency caesarean section and was directly shifted to the obstetric ICU where she expired after $24 \mathrm{~h}$ due to septicaemic shock.

TABLE 3. When primary indications for ICU admission were analyzed, hemodynamic instability $(n=20,83.33 \%)$ was the most common and significant cause of admission to ICU as compared to respiratory insufficiency $(n=3,12.54 \%)$ and neurological dysfunction $(n=1$, $4.16 \%), \mathrm{P}=0.000$. However, during the course of treatment $22(91.66 \%)$ patients required inotropic 
support (vasopressors) and $17(70.83 \%)$ patients required ventilatory support, but these interventions were not found to be a significant risk factor for mortality $(\mathrm{P}>0.05)$. Out of the 17 patients requiring ventilator support there were 8 (47.05\%) survivors and 9 (52.94\%) non-survivors. The mean duration of ventilation was $30.17 \pm 21.65 \mathrm{~h}$ (range 0.5-96 h) with survivors having significantly longer duration of controlled ventilation $(41.14 \pm 28.54 \mathrm{~h})$, as compared to non-survivors $(20.56 \pm 22.25 \mathrm{~h}, \mathrm{P}=0.01)$.The mean duration of stay in the ICU was $39.42 \pm 33.70 \mathrm{~h}$ (range $2-144 \mathrm{~h}$ ) with significantly longer duration of stay in survivors $(50.86 \pm 36.6 \mathrm{~h})$, as compared to non-survivors $(23.40 \pm 21.681 \mathrm{~h}, \mathrm{P}=0.000)$.Maternal outcome according to patient diagnosis showed that obstetric hemorrhage $(\mathrm{n}=15,62.50 \%)$ was the most important cause for ICU admission $(\mathrm{P}=0.000)$ but none of the diagnosis was found to be a significant risk factor for maternal mortality $(\mathrm{P}>0.05)$. Multi-organ dysfunction syndrome $(\mathrm{n}=8,80 \%)$ was found to be the most significant $(\mathrm{P}=0.008)$ cause of maternal mortality, while other causes were disseminated intravascular coagulation $(n=1,10 \%)$ and septic shock syndrome $(n=1,10 \%)$. Distribution of patients according to the MPM II predicted death rate at various time intervals along with their outcome was also noted. A progressive rise in predicted death rate was seen in most of the non survivors and a fall was seen in most of the patients who were shifted to the wards after stabilization.

DISCUSSION: Clinical recognition of the unique needs of the critically ill obstetric patients have received much attention in an attempt to assess the need for dedicated critical care facilities 7,8 . Since, in general, for most obstetric patients, rapid recovery follows correction of the acute insult. It is now believed that between $0.1 \%$ and $0.9 \%$ of parturients have complications requiring ICU admission ${ }^{9}$. On analysis of the critically ill obstetric patients in our hospital for a year, we found good amount of ICU admissions ( $n=24,0.14 \%)$ in spite of the high maternal mortality. A delay in identification of critical patients could be a major cause for underutilization of the ICU and in turn maternal mortality. A higher utilization of ICU services in the developed countries has been observed (1.40) ${ }^{10}$. Obstetric patients are usually young but the gestational age of critically ill parturients shows a variance in different studies 11-13. In our study most of the parturients at term (36 weeks) were admitted for obstetric hemorrhage, while in the studies from developed countries, they were admitted for preeclampsia (29 weeks, 29.6 weeks, 31.7 weeks) which could explain this difference in gestational age. Low socioeconomic status, lack of education and poor antenatal care has been found to have a considerable effect on obstetric complications and outcome. However, we could not find any association with factors like level of literacy, rural/ urban background, and distance travelled for reaching the hospital with higher incidence of ICU admission or poor outcome.

The lack of antenatal care has not been associated as a risk factor for ICU admissions as was also observed in our study. It has been reported 14, 15, that the most common reasons for ICU admissions for obstetric patients are hypertensive disorders and massive obstetric hemorrhage. It was emphasized that early detection and prompt referral to tertiary centers with intensive care facilities to provide optimum care of circulation, blood pressure and ventilation could minimize the prevalence of multiple organ failure and mortality in critically ill obstetric patients. Our study group revealed a higher rate of obstetric rather than medical complications. As reported by other studies ${ }^{16}$, we observed that obstetric hemorrhage was the major cause for ICU admission. In our series, it represented the main cause for ICU admission (62.5\%). At the same time, in comparison with other authors ${ }^{17}$, we found a lower percentage of pre-eclampsia and eclampsia. Most of the authors have 
reported a higher incidence of postpartum admission to the obstetric ICU (78\%) ${ }^{18}$ as was also seen in our study (83.3\%). This could be attributed to the hemodynamic changes in the postpartum period which shows a $65 \%$ increase in cardiac output, acute blood loss during delivery and decrease in plasma oncotic pressure ${ }^{19}$. Though hemodynamic instability can usually be managed in the labor room area, but the need for mechanical ventilation remains the major indication for antenatal ICU transfer. After delivery, criteria for ICU transfer become generalized since services of obstetricians are no more a priority. In our study, ventilator support was a major indication for ICU admissions among antenatal patients with pregnancy-induced hypertensive disorders $(n=3 / 4,75 \%)$.

It has been observed that hemodynamic and respiratory complications needing inotropic or ventilator support remain the most common reasons for ICU admissions and the need for support may predict poor outcome. In the present study, 91.66\% patients required inotropic support and $70.83 \%$ required ventilatory support. Although not statistically significant, the association of mortality with both these supports was considerable (10/22 and 9/17 respectively). The mean duration of ventilation and ICU stay was apparently less in our study than others ${ }^{20-22}$ which could be attributed to the higher mortality rate $(41.67 \%)$ in our study. Incidence of maternal mortality has significantly decreased in the developed countries $(11 \%, 27.78 \%)$ as compared to the developing countries (50\%, 40.35\%). Increased maternal mortality rates in developing countries have been attributed to treatment by quacks, low socio-economic status, non-existent antenatal care, low hematocrit and under-nourishment in obstetric patients. Our maternal mortality was $41.67 \%$; we found multi-organ failure including heart failure, shock lung and acute renal failure to be the leading cause of maternal mortality (80\%) as reported earlier.

It has been observed that if antepartum mothers had a live fetus with gestational age more than 32 weeks and was delivered promptly without undue delay, while under intensive care there would not be higher incidence of neonatal mortality. In our study there were four antenatal patients with pregnancy induced hypertension (PIH) with intrauterine death and delivery was conducted in ICU. Patients who were admitted with obstetric hemorrhage $(n=15)$ had significantly better fetal survival $(\mathrm{n}=12(80 \%), \mathrm{P}=0.019)$.

CONCLUSION: We conclude that obstetric hemorrhage leading to hemodynamic instability remains the leading cause of ICU admissions. Inotropic support and ventilatory support are the main interventions provided in the ICU, which were not found to be associated with poor outcome. Duration of ventilation and stay in the ICU were significantly more in the survivors. Focusing on audit of obstetric ICUs in India will help to reduce the maternal morbidity and mortality significantly in the near future, by improving patient care and stimulating education in the management of critically ill patients among the resident doctors, consultants and nursing staff. A better scoring system especially applicable to the critically ill obstetric patients in the Indian scenario could lead to accurate monitoring of quality care and risk stratification for clinical and therapeutic trials.

\section{REFERENCES:}

1. Gilbert TT, Smulian JC, Martin AA, Ananth CV, Scorza W, Scardella AT, et al. Obstetric admissions to the intensive care unit: Outcome and severity of illness. Obstet Gynecol.2003; 102:897-903.

2. Naylor DF, Jr, Olson MM. Critical care obstetrics and gynecology. Crit Care Clin.2003; 19:127-49. 
3. Strand K, Flaatten H. Severity scoring in the ICU: A review. Acta Anaesthesiol Scand.2008; 52:467-78.

4. El-Solh AA, Gran BJ. A comparison of severity of illness scoring systems for critically ill obstetric patients. Chest. 1996; 110:1299-304.

5. Osinaike B, Amanor-Boadu S, Sanusi A. Obstetric intensive care: A developing country experience. Internet J Anesthesiol. 2006;Vol. 10

6. Tempe A, Wadhwa L, Gupta S, Bansal S, Satyanarayana L. Prediction of mortality and morbidity by Simplified Acute Physiology Score (SAPS II) in obstetric intensive care unit admissions. Indian J Med Sci. 2007; 61:179-85.

7. Cheng C, Raman S. Intensive care use by critically ill obstetric patients; a five year review. Int J Obstet Anesth. 2003; 12:89-92.

8. Loverro G, Pansini V, Greco P, Vimercati A, Parisi AM, Selvaggi L. Indications and outcome for intensive care unit admission during puerperium. Arch Gynecol Obstet.2001;265:195

9. Quah TC, Chiu JW, Tan KH, Yeo SW, Tan HM. Obstetric admissions to the intensive therapy unit of a tertiary care institution. Ann Acad Med Singapore. 2001; 30:250-3.

10. Keizer JL, Zwart JJ, Meerman RH, Harinck BI, Feuth HD, van Roosmalen J. Obstetric intensive care admissions: A 12 year review in a tertiary care centre. Eur J Obstet Gynecol Reprod Biol. 2006; 128:152-6.

11. Vasquez DN, Estenssoro E, Canales HS, Reina R, Saenz MG, Das Neves AV, et al. Clinical characteristics and outcomes of obstetric patients requiring ICU admissions. Chest.2007; 131:718-24.

12. Kilpatrick SJ, Matthay MA. Obstetric patients requiring critical care: A five year review. Chest. 1992; 101:1407-12.

13. Lapinsky SE, Kruczynski K, Seaward GR, Farine D, Grossman RF. Critical care management of the obstetric patient. Can J Anaesth. 1997; 44:325-9.

14. Price LC, Germain S, Wyncoll D, Nelson Piercy C. Management of the critically ill obstetric patient. Obs Gynae Reprod Med. 2009; 19:350-8.

15. Zeeman GG. Obstetric critical care: A blue print for improved outcomes. Crit Care Med.2006; 34:S208-14.

16. Tang LC, Kwok AC, Wong AY, Lee YY, Sun KO, So AP. Critical care in obstetrical patients: An eight-year review. Chin Med J. 1997; 110:936-941.

17. Okafor UV, Efetie ER. Critical care obstetrics in a developing country. J Turkish-German Gynecol Assoc. 2008; 9:9-13.

18. Mahutte NG, Murphy-Kaulbeck L, Le Q, Solomon J, Benjamin A, Boyd ME. Obstetric admissions to the intensive care unit. Obstet Gynecol. 1999; 94:263-6.

19. Ueland K, Hansen JM. Maternal cardiovascular dynamics. Labor and delivery under local and caudal analgesia. Am J Obstet Gynecol. 1969; 103:8-18.

20. Graham SG, Laxton MC. The requirement for intensive care support for the pregnant population. Anaesthesia. 1989;44:581-4.

21. Collop NA, Sahn SA. Critical illness in pregnancy. Chest. 1993;103:1548-52.

22. Monaco TJ, Jr, Spielman FJ, Katz VL. Pregnant patients in the intensive care unit: A descriptive analysis. South Med J. 1993;86:414-7. 


\begin{tabular}{|c|c|c|c|c|c|}
\hline \multicolumn{2}{|c|}{ Characteristic feature } & \multirow{2}{*}{$\begin{array}{c}\text { Total (\%) } \\
24\end{array}$} & \multirow{2}{*}{$\begin{array}{c}\begin{array}{c}\text { Survivors } \\
\text { (\%) }\end{array} \\
14(58.33)\end{array}$} & \multirow{2}{*}{$\begin{array}{c}\begin{array}{c}\text { Non-Survivors } \\
(\%)\end{array} \\
10(41.67)\end{array}$} & \multirow{2}{*}{ 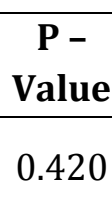 } \\
\hline $\begin{array}{c}\text { Number of } \\
\text { patients }\end{array}$ & & & & & \\
\hline \multirow{3}{*}{ Age in years } & $\leq 20$ & $2(8.33)$ & $2(8.16)$ & 0 & 0.153 \\
\hline & $21-30^{*}$ & $18(75)$ & $10(42)$ & $8(33.33)$ & 0.348 \\
\hline & $\leq 31$ & $4(16.67)$ & $2(8.16)$ & $2 .(8.33)$ & 0.305 \\
\hline \multirow{2}{*}{ Literacy } & Educated & $11(45.83)$ & $7(29.16)$ & $4(16.6)$ & 0.128 \\
\hline & Un - Educated & $13(54.17)$ & $7(29.16)$ & $6(25)$ & 0.688 \\
\hline \multirow{2}{*}{ Background } & Rural & 13(54.17) & $9(37.50)$ & $4(16.66)$ & 0.162 \\
\hline & Urban & $11(45.83)$ & $5(21.03)$ & $6(25)$ & 0.688 \\
\hline \multirow{2}{*}{ Antenatal care } & Booked $^{* *}$ & $19(79.17)$ & $11(45.83)$ & $8(33.33)$ & 0.499 \\
\hline & Un -Booked & $5(20.83)$ & $3(12.5)$ & $2(8.33)$ & 0.642 \\
\hline \multirow{3}{*}{ Parity } & Para one & $13(54.16)$ & $8(33.3)$ & $5(20.83)$ & 0.410 \\
\hline & Para two & $7(29.16)$ & $3(12.5)$ & $4(16.67)$ & 0.672 \\
\hline & Para three & $4(16.68)$ & $3(12.5)$ & $1(4.16)$ & 0.319 \\
\hline \multirow[b]{2}{*}{ Distance } & Less than $50 \mathrm{~km}$ & $16(66.97)$ & $11(45.83)$ & $5(20.83)$ & 0.487 \\
\hline & $\begin{array}{c}\text { More } \\
\text { than50km }\end{array}$ & $8(33.3)$ & $3(12.5)$ & $5(20.83)$ & 0.487 \\
\hline
\end{tabular}

*Data are expressed as $\mathrm{n}(\%),{ }^{*} \mathrm{P}=0.000,{ }^{* *} \mathrm{P}=0.005$.

\begin{tabular}{|c|c|c|c|c|c|}
\hline Complications & Diagnosis & $\begin{array}{c}\text { Total no. of } \\
\text { Patients } \\
n=24\end{array}$ & $\begin{array}{c}\text { Admitted } \\
\text { from } 0 T \\
n=13 \\
(54.16 \%)\end{array}$ & $\begin{array}{c}\text { Admitted } \\
\text { from wards } \\
n=11 \\
(45.84 \%)\end{array}$ & P-Value \\
\hline \multirow{4}{*}{$\begin{array}{c}\text { Obstetric } \\
\text { complications }(\mathrm{n}=22 \text {, } \\
91.66 \%)\end{array}$} & $\begin{array}{c}\text { Obstetric } \\
\text { hemorrhage* }^{*}\end{array}$ & $15(62.5)$ & $10(42)$ & $5(20.83)$ & 0.194 \\
\hline & $\begin{array}{c}\text { Pregnancy } \\
\text { induced } \\
\text { hypertension }\end{array}$ & $4(16.66)$ & 0 & $4(16.66)$ & 0.318 \\
\hline & $\begin{array}{c}\text { Pulmonary } \\
\text { embolism }\end{array}$ & $1(4.16)$ & 0 & $1(4.16)$ & 0.318 \\
\hline & Septicemia & $2(8.33)$ & $2(8.33)$ & 0 & 0.153 \\
\hline $\begin{array}{c}\text { Non-obstetric } \\
\text { complications }(\mathrm{n}=2 \text {, } \\
8.34 \%)\end{array}$ & Pulmonary edema & $2(8.33)$ & $1(4.16)$ & $1(4.16)$ & 0.305 \\
\hline
\end{tabular}

*data are expressed as n (\%), $\mathrm{P}=0.000$. 


\section{AUTHORS:}

1. M. Vijayasree

2. K. Madhuri

3. N.C.H. Venugopal

4. T. Narasinga Reddy

5. Dilip Rampure

\section{PARTICULARS OF CONTRIBUTORS:}

1. Professor, Department of Gynaecology and Obstetrics, Mamata Medical College \& General Hospital, Khammam.

2. Associate Professor, Department of Gynaecology and Obstetrics, Mamata Medical College \& General Hospital, Khammam.

3. Professor, Department of Anaesthesia, Mamata Medical College \& General Hospital, Khammam.
4. Professor, Department of Radiology, Mamata Medical College \& General Hospital, Khammam.

5. Professor, Department of General Medicine, Mamata Medical College \& General Hospital, Khammam.

\section{NAME ADDRESS EMAIL ID OF THE CORRESPONDING AUTHOR:}

Dr. M. Vijayasree, Telangana Hospitals, Balaji Nagar,

Khammam - 507001, Andhra Pradesh, India.

Email - mamatakhmm@gmail.com

Date of Submission: 23/12/2013.

Date of Peer Review: 24/12/2013.

Date of Acceptance: 07/01/2014.

Date of Publishing: 14/01/2014. 